\title{
Dielectric properties of milk during ultra-heat treatment
}

*Israel Muñoz ${ }^{(1)}$, Pere Gou ${ }^{(1)}$, Pierre A. Picouet ${ }^{(2)}$, Antoni Barlabé(3) Xavier Felipe $^{(1)}$

(1) IRTA-TA, Food processing and Engineering, Finca Camps i Armet 17121 Monells, Girona, Spain

(2). USC 1422 GRAPPE, INRA, Ecole Supérieure d'Agricultures, Univ. Bretagne Loire, SFR 4207 QUASAV, 55 rue Rabelais 49100 Angers, France.

(3) Universitat Politècnica de Catalunya (Barcelona Tech). Department of Signal Theory and Communications. Jordi Girona 1-3. 08034 Barcelona, Spain.

* Corresponding author. E-mail address: israel.munoz@irta.cat 


\begin{abstract}
Dielectric properties are important for predicting dielectric heating of foodstuffs. The dielectric properties of three types of milk (raw, skimmed and concentrated non-fat) were analyzed at high frequencies between $10 \mathrm{MHz}$ to $2450 \mathrm{MHz}$ for producing temperatures between $20^{\circ} \mathrm{C}$ and $150{ }^{\circ} \mathrm{C}$. The study of cow milk dielectric constants $(\varepsilon '$ and $\varepsilon ")$ at conditions above $100{ }^{\circ} \mathrm{C}$ is needed to evaluate dielectric sterilization of milk. The dielectric constant $\left(\varepsilon^{\prime}\right)$ was found to decrease with frequency at all temperatures but increase with temperature at low frequencies and decrease with temperature at high frequencies. The dielectric loss factor ( $(")$ decreased with frequency and increased with temperature in almost the entire range of frequencies. Ionic conduction was the dominant mechanism across most of the frequency range. For milk samples with higher ash content (related to salt content), $\varepsilon$ ' was higher at low frequencies and lower at high frequencies, whereas $\varepsilon$ " was higher for all frequencies. Penetration depth was lower for milk samples with higher ash content.
\end{abstract}

Keywords : milk, dielectric properties, UHT, dielectric heating, ash content

\title{
1. Introduction
}

Milk is an important foodstuff for humans. Raw milk can be contaminated with microorganisms that are naturally present at the animal farm and processing facilities. Pasteurization and sterilization treatments are used to guarantee product safety and extend shelf life. Typically, the pasteurization of milk, known as HTST (High Temperature and Short Time) involves heating milk to $72{ }^{\circ} \mathrm{C}$ and maintaining this temperature for 15 seconds (FAO 2004). The sterilization of milk, known as UHT (ultra-heat temperature) involves heating milk to $140{ }^{\circ} \mathrm{C}$ and maintaining this temperature for 1.9 seconds (FAO 2004).

In conventional milk processing, milk heating is achieved by transferring heat from steam to the milk using heat exchangers. A problem with heat exchangers is fouling, caused mainly by protein denaturization and precipitation of minerals. Fouling decreases heat transfer, thus affecting milk safety if the required temperature may not be achieved. Moreover, fouling increases energy consumption and the heating system must 
be cleaned more frequently, increasing the cost of energy; labour and chemical products (Gillham et al., 2000).

Technologies have been developed to reduce fouling problems in milk pasteurization or sterilization. One of these is dielectric heating, which involves transferring heat in the form of electromagnetic waves instead of through the wall of a heat exchanger (convection and conduction). In food industries, the two most common dielectric heating technologies use microwaves $(\mu \mathrm{W})$ and radiofrequency (RF) waves. Some of the advantages of these over conventional methods are: higher heating rates inside the product that reduces processing time and energy costs; ultrafast heat treatment that minimises loss of nutrients and organoleptic properties; reduced fouling deposition; and higher heating efficiency and lower maintenance cost (Ahmed and Ramaswamy, 2007). For instance, RF equipment from Cartigliano (Vicenza, Italy) can heat liquids up to 20 ${ }^{\circ} \mathrm{C}$ in less than 2 seconds.

For designing dielectric heating systems, it is important to predict how the electromagnetic fields will affect the heat generation in the product. Dielectric properties of a material are some of the most important parameters for this purpose (Datta and Anantheswaran, 2001), the most important of which is the relative complex permittivity, which can be expressed as:

$\varepsilon=\varepsilon^{\prime}-\mathrm{j} \varepsilon^{\prime \prime}$

where,

$\varepsilon$ is the relative complex permittivity (no units);

$\varepsilon$ ' relative real permittivity (no units), also known as dielectric constant;

$\varepsilon^{\prime \prime}$ is the relative loss factor (no units), also known as dielectric loss factor; and

$\mathrm{j}$ is equal to $\sqrt{-1}$.

The dielectric constant represents the ability of the material to store electrical energy. The dielectric loss factor is related to various mechanisms of energy dissipation in which electric energy is transformed into heat (Ryynänen, 1995). If heat losses are insignificant, the rate of change in temperature $d T / d t$ of any material can be calculated as follows (Nelson 1996): 


$$
\begin{gathered}
P=55.63 \times 10^{-12} f E^{2} \varepsilon^{\prime \prime} \\
\frac{d T}{d t}=\frac{P}{c_{p} \rho}
\end{gathered}
$$

where,

$P$ is the power dissipated per unit of volume $\left(\mathrm{W} / \mathrm{m}^{3}\right)$;

$f$ is the frequency of the electromagnetic field $(\mathrm{Hz})$;

$E$ is the root mean square electric field intensity $(\mathrm{V} / \mathrm{m})$;

$d T / d t$ is the rate of temperature increase $\left({ }^{\circ} \mathrm{K} / \mathrm{s}\right)$;

$c_{p}$ is the specific heat $\left(\mathrm{J} /\left(\mathrm{kg} \cdot{ }^{\circ} \mathrm{K}\right)\right)$; and

$\rho$ its density $\left(\mathrm{kg} / \mathrm{m}^{3}\right)$.

Dielectric permittivity changes with the temperature of the fluid and frequency of the treatment waves. For this reason it is important to study the variation of dielectric properties of foodstuffs with temperature and frequency.

Several studies on the dielectric properties of liquid foodstuffs can be found in the literature. These works have studied the dielectric properties, at several temperatures and frequencies, of soy sauce (Tanaka et al., 2005), fruit juices (Garcia et al, 2001; Zhu at al., 2012), liquid whey protein mixture (Wang et al., 2003), and others. The dielectric properties of milk have also been studied (To et al., 1974; Coronel, 2003; Nunes et al., 2006; Guo et al., 2010; Zhu et al., 2014; Zhu et al, 2015a), however, not at temperatures above $90^{\circ} \mathrm{C}$, which are needed to predict heating in dielectric sterilization processes above $100{ }^{\circ} \mathrm{C}$. The objective of this work was to study the dielectric properties of raw milk (RM), skimmed milk (SM) and 35\% concentrated non-fat milk (CNFM), at temperatures ranging from 20 to $150{ }^{\circ} \mathrm{C}$, at a constant pressure of 4 bars, and for frequencies of between 10 and $2450 \mathrm{MHz}$. These are the operating parameters of conventional industrial $\mu \mathrm{W}$ and RF equipment. Special attention was given to the frequencies allowed for industrial, scientific and medical (I.S.M.) applications: 27.12 $\mathrm{MHz}, 40.68 \mathrm{MHz}, 433 \mathrm{MHz}, 915 \mathrm{MHz}$ and $2450 \mathrm{MHz}$.

\section{Materials and methods}




\subsection{Milk samples}

RM was purchased from a local producer (Cruilles, Catalonia, Spain). During transportation, samples were kept refrigerated at $4{ }^{\circ} \mathrm{C}$. SM was obtained from the same RM sample using a skimmer (Elecrem ' 1 ', Fresnes, France) which reduced the fat content to below 1\%. CNFM (35\% concentration) was obtained by mixing 130 liters of water at $40-45{ }^{\circ} \mathrm{C}$ and $70 \mathrm{~kg}$ of low heat dry-milk (Lactalis Ingredients, Bougbarré, France) in a tank. The mixture was stirred at 156 r.p.m. for 30 minutes.

Table 1 shows the composition of the milk samples. For the RM and SM samples, the composition was determined using a Milkoscan Minor (Type 78100, FOSS, Hillerød, Denmark). For the CNFM sample, the composition was calculated from the composition of dry-milk provided by Lactalis Ingredients and the percentage of added water.

\subsection{Measurement of dielectric properties}

Dielectric measurements were performed with an open-ended coaxial-line probe (model $85070 \mathrm{E}$ ) and high temperature probe, connected to a $300 \mathrm{KHz}-20 \mathrm{GHz}$ network analyser (model E5071C) through an $300 \mathrm{kHz}-26.5 \mathrm{GHz}$ electronic calibration module (Agilent N4691-60006). All these devices were from Agilent Technologies, Santa Clara, USA. The connection between the probe and the electronic calibrator was via a semi-rigid, short (14 cm long), coaxial cable special for high temperature and high frequency applications, which was fan-cooled for even higher thermal stability (Micro Coax UT-085C-TP-LL, Pottstown, USA). Even at the maximum autoclave temperature $\left(150^{\circ} \mathrm{C}\right)$, the maximum outer temperature of the cable was $60{ }^{\circ} \mathrm{C}$ at the probe connector and $25{ }^{\circ} \mathrm{C}$ at the electronic calibrator connector. In that way, the electronic calibration module was kept at room temperature, ensuring its correct operation. Connecting the electronic calibrator and the network analyser, was a flexible $\mu \mathrm{W}$ test cable (MiniCircuits CBL-1M-SMSM+, New York, USA). SMA gold plated, high quality $\mathrm{RF} / \mu \mathrm{W}$ connectors (Huber+Suhner 11_SMA-50-2-15/111_NE, Pfäffikon, Switzerland) were used for all system components.

The Electronic Calibration Module (controlled by the Agilent 85070 E probe software) refreshed the calibration just prior to each measurement being made. This virtually 
eliminated cable instability (i.e. cable movement) and system drift errors (Agilent Technologies, 2012).

\subsection{Preliminary study of autoclave and test set-up}

Prior to construction of the autoclave, the placement of the probes inside the autoclave and the influence of the metallic walls on the measurements was thoroughly studied.

The dielectric constant and the dielectric loss factor was derived from the measurement of the reflection coefficient at the liquid (milk), by the coaxial transmission line (RF probe) interface. Therefore, it was necessary to ensure that no other reflections disturbed the measurements. Due to the shape of the RF probe (which acts as a coaxial aperture antenna), reflections were caused by the autoclave wall in front of the probe. Reflections from the lateral and rear walls are very small. Reflection from a metal surface is higher than from the liquid - air interface. To observe the real effects of the autoclave walls on the measurements, a test setup was built (Fig. 1). Metallic plates, f1, $\mathrm{f} 2$ and $\mathrm{f} 3$, were situated at distances, $\mathrm{d} 1, \mathrm{~d} 2$ and $\mathrm{d} 3$ respectively, from the RF probe. The measuring instrument, i.e., the automatic vector network analyser Agilent E5071C (Santa Clara, USA), was adjusted for continuous measurement of the reflection coefficient and complex dielectric constant. Measurements were taken over a frequency range of $10-2450 \mathrm{MHz}$ with a $-10 \mathrm{dBm}$ RF output power. Each plate was independently moved, progressively increasing the distance from the probe, until no variation in the measurement was observed. The procedure was repeated with different types of metallic plates (copper, aluminium), with different sizes of container (big and small, made of glass), with different types of liquid (milk, distilled water), and with different liquid levels (different $\mathrm{d} 4$ distances). The temperature probe was also placed at different places near and far from the RF probe. As expected, the frontal plate (f1) was responsible for the most reflection. The lateral (f2) and back (f3) plates had a very little influence. The temperature probe and the liquid-air interface also had very little influence on the signal.

The above-mentioned procedure was repeated for different temperatures (below 100 ${ }^{\circ} \mathrm{C}$ ), produced using a heater (b). A thermal shield (teflon plate) was used to avoid heating the electronic calibrator. It was also important to avoid the possible build-up of bubbles in the milk, seriously affecting the measurements by sticking to the surface of the RF probe. 
From this initial testing, the following minimum dimensions were set for the autoclave manufacture: $\mathrm{d} 3=\mathrm{d} 4=5 \mathrm{~mm} ; \mathrm{d} 2=10 \mathrm{~mm} ; \mathrm{d} 1=50 \mathrm{~mm}$. The tip of the temperature probe was placed $5 \mathrm{~mm}$ behind and $5 \mathrm{~mm}$ laterally from the RF probe. This location did not interfere with the RF probe measurements. The RF probe was placed horizontally to minimize the risk of bubbles on the probe.

\subsection{Autoclave description}

A small autoclave (Bigas Alsina S.A, Girona, Spain) was built to enable measurement of dielectric constants above $100{ }^{\circ} \mathrm{C}$. It had a capacity of $750 \mathrm{ml}$ (Fig. 2) and was built in stainless steel (316 L-S), $106 \mathrm{~mm}$ in height and $108 \mathrm{~mm}$ in diameter. There were two inlets for inserting the two probes (dielectric probe and the temperature probe). Both inlets were $37 \mathrm{~mm}$ from the base and $25 \mathrm{~mm}$ apart. An additional inlet was available for connecting a compressed air hose. The vessel could be pressurised to a constant pressure during the experiment. The autoclave contents (the milk) were heated via a heating jacket containing thermal oil, which was heated by an electrical resistance controlled by a potentiometer..

\subsection{Experimental procedure}

To guarantee uniform temperature distribution throughout the sample, the sample was heated very slowly by adjusting the potentiometer control. A set of dielectric measurements were taken over a one-hour heating period (from $20^{\circ} \mathrm{C}$ to $150^{\circ} \mathrm{C}$ ). Each RF measurement $(10-2450 \mathrm{MHz})$ took around 10 seconds. During a RF measurement an increase of less than $0.1{ }^{\circ} \mathrm{C}$ (thermometer resolution) was observed with the temperature probe (TESTO, Lenzkirch, Germany). This ensures a uniform temperature distribution near the RF probe while measuring.

The experimental procedure had the following steps:

1) The network analyser was warmed-up for 60 minutes. The system was set-up for recording 301 points across the frequency range 10 and $2450 \mathrm{MHz}$. As the measuring method is less accurate at lower frequencies (10-100 MHz), many measuring points were taken at lower frequency range to counter the problem.

2) The RF instrument was calibrated with the RF probe using the standard OSL (Open Short- Load) RF / $\mu \mathrm{W}$ calibration technique. The open circuit was obtained by leaving the RF probe free in the air. The short circuit was obtained by connecting to the RF 
probe a special add-on (supplied by the manufacturer in the Agilent $8050 \mathrm{E}$ probe kit, Santa Clara, USA) that mechanically short-circuited the probe. The load was distilled water.

3) The system was tested by taking measurements of distilled water at ambient temperature and comparing the result with reference data.

4) The water was removed from the autoclave and replaced with a $500 \mathrm{ml}$ sample of milk. The autoclave was tightly closed and the inner pressure increased to, and maintained at, 4 bar throughout the experiment, using a built-in manometer. In this way, the milk did not boil when the temperature was increased to $150^{\circ} \mathrm{C}$, thus minimizing the amount of water evaporated from the sample to the void.

5) The temperature was increased very slowly from $20^{\circ} \mathrm{C}$ to $150^{\circ} \mathrm{C}$ by adjusting the potentiometer and monitoring it with the temperature probe.

6) Dielectric properties were measured every $10{ }^{\circ} \mathrm{C}$, with two measurements taken at each temperature point.

7) After the last measurement at $150{ }^{\circ} \mathrm{C}$, the autoclave was left to cool to room temperature (at least one hour) and then depressurized. Next, the milk removed and the autoclave cleaned.

This procedure was repeated twice for each milk type.

\subsection{Penetration depth}

The main measurement parameters of the study were the dielectric constant $\varepsilon$ ' and the dielectric loss factor $\varepsilon "$. The change in these properties at different temperature and frequency was evaluated. Once these properties had been derived, the penetration depth of the treatment waves into milk was also derived.

Penetration depth $\left(d_{p}\right)$ (Feynman et al., 2005) is the depth from the surface of the product at which the power density has decreased by $37 \%$. $d_{p}(m)$ can be calculated from the dielectric constant and loss factor using the following formula: 


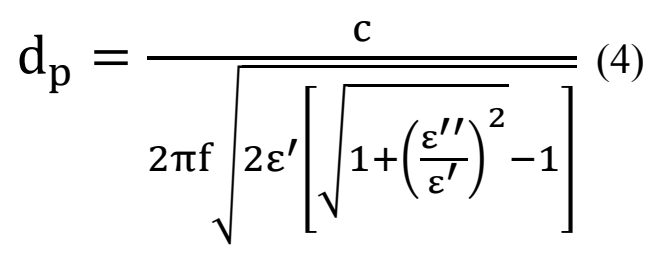

where,

$\mathrm{c}$ is the speed of the light in free space $\left(3 \times 10^{8} \mathrm{~m} / \mathrm{s}\right)$; and

$f$ is the frequency $(\mathrm{Hz})$.

The penetration depth parameter is useful for determining the appropriate depth of liquid which can be adequately heated using dielectric heating. According to Schiffman (1995), this should not exceed 2 or 3 times the penetration depth in order to guarantee uniform heating. $d_{p}$ was derived for the three different types of milk over the same temperature and frequency ranges.

\section{Results and discussion}

\subsection{Dielectric constants}

The dielectric constant and loss factor for the RM, SM and CNFM samples, at frequencies of $27.12 \mathrm{MHz}, 40.68 \mathrm{MHz}, 433 \mathrm{MHz}, 915 \mathrm{MHz}$ and $2450 \mathrm{MHz}$, and for temperatures ranging from $20{ }^{\circ} \mathrm{C}$ to $150{ }^{\circ} \mathrm{C}$ are shown in Table 2. Fig. 3 shows the dielectric constant for RM, for frequencies ranging from $10 \mathrm{MHz}$ to $2450 \mathrm{MHz}$. Similar curves were obtained for the other types of milk (figures not shown).

The dielectric constant decreased with frequency at all temperatures. The reduction in the dielectric constant was more pronounced for frequencies below $100 \mathrm{MHz}$. Above $500 \mathrm{MHz}$, the dielectric constant tended to fall gently. This reduction was higher at high temperatures than at low temperatures. For example, for $\mathrm{RM}$, at $150{ }^{\circ} \mathrm{C}$ the dielectric constant decreased from 138.9 at $27.12 \mathrm{MHz}$ to 39.2 at $2450 \mathrm{MHz}$, whereas at $20{ }^{\circ} \mathrm{C}$ it decreased from 90.3 MHz to 68.6 MHz. Similar trends had previously been observed in high water content foodstuffs such as liquid whey protein mixture, cooked macaroni noodles, cheese sauce (Wang et al., 2003), smashed potatoes (Guan et al., 2004), salmon fillet (Wang et al., 2008) or fruits (Nelson et al., 2002). According to Barba and d'Amore (2012), who analysed reductions in the dielectric constant with temperature for distilled water at low frequencies, water dipoles follow the variations of the field. In this situation, dipoles store the maximum energy and the dielectric constant has the highest value. As frequency increases, the dipoles are less able to follow oscillations in the field and their storage capability decreases, decreasing the dielectric constant value. The 
dielectric constants were similar to those of Coronel et al. (2003) at $915 \mathrm{MHz}$ for processed SM.

At the lower RF frequencies $(27.12 \mathrm{MHz})$ dielectric constant tended to increase with temperature, whereas at the higher $\mu \mathrm{W}$ frequencies $(2450 \mathrm{MHz})$ the dielectric constant tended to decrease with temperature. According to Barba and d'Amore (2012), the presence of bound water and salts makes the dielectric constant increase with temperature at low frequencies. In other studies of liquid whey protein mixture and cheese sauce (Wang et al., 2003), dielectric constants were also found to increase with temperatures at low frequencies. This change from a decreasing to an increasing response with temperature took place between 50 to $200 \mathrm{MHz}$, and varied with the type of milk. Previous studies also stated that the frequency at which the change in the temperature trend switches depends on the product analysed. For example, it is 55.97 $\mathrm{MHz}$ for smashed potatoes (Guan et al., 2004), 90-100 MHz for whole eggs (Wang et al., 2009) or $480 \mathrm{MHz}$ for bentonite water pastes (Luan et al., 2015).

However, this change was not observed by Zhu et al. (2012) for fruit juices in the range 20-4500 MHz and by Zhu et al. (2014, 2015a) for milk in the range 10-4500 MHz. In these works, dielectric constant decreases with temperature across the whole range of frequencies. These results were also observed for pure water (Kaatze, 1989). One possible reason for the contradictory results of Zhu et al. (2014, 2015a) for milk was that the glass centrifuge tubes in which the measurements were taken were too small and the walls may have distorted the results. In our work, the effects of the autoclave walls on the measurements were taken into consideration in the autoclave's design (section 2.3).

At RF frequencies, the highest dielectric constants were observed for CNFM, and the values for RM and SM were similar. Whereas at $\mu \mathrm{W}$ frequencies, CNFM had the lowest dielectric constants, and they were similar for RM and SM. According to Komarov et al. (2005), dielectric constants decrease rapidly with decreasing moisture content, which was also observed in milk (Nunes et al., 2006) at $\mu \mathrm{W}$ frequencies. Dielectric constants also tend to increase with increasing ash content at RF frequencies, whereas they tend to fall with ash content at $\mu \mathrm{W}$ frequencies. For example, for saline solutions this change relative to pure water is observed at $915 \mathrm{MHz}$. At $\mu \mathrm{W}$ frequencies, dielectric constants of saline solutions decrease with temperature from $40{ }^{\circ} \mathrm{C}$ to $140{ }^{\circ} \mathrm{C}$ (Ohlsson and 
Bengtsson, 1975). At $\mu \mathrm{W}$ frequencies, salts (related to ash content) dissolve and form ions which in turn bind the water molecules and reduce water polarization and decrease the dielectric constant (Mugget, 1995). The higher ash content of CNFM may explain the change in the dielectric constant for this type of milk and offset the effects of lower water content of this milk. Fat and protein are relatively inert to electromagnetic waves (Ryynänen, 1995; Mudgett and Westphal, 1989). Fat depresses the dielectric constant as the amount of free water is reduced in the system. This might have some impact on the results, but salt content is the main factor. The dielectric constant of RM was slightly higher than that of SM. This difference may be explained by the slightly different composition (water and ash content) of both types of milk, and the uncertainty of the measurement method.

\subsection{Dielectric loss factor}

Fig. 4 shows the dielectric loss factor at different frequencies and temperatures. The loss factor of the three milk types tended to decrease with frequency. For frequencies of 27.12 MHz, 40.60 MHz, 433 MHz and 915 MHz, the dielectric loss factor increased with temperature. However, for $2450 \mathrm{MHz}$ it fell gently with temperature from $20^{\circ} \mathrm{C}$ to $60{ }^{\circ} \mathrm{C}$ and increased above $60^{\circ} \mathrm{C}$ for RM and SM, whereas for CNFM it increased with temperature across the whole range. At low frequencies $(27.12 \mathrm{MHz})$, the dielectric loss factor increased across the temperature range from $20^{\circ} \mathrm{C}$ to $150{ }^{\circ} \mathrm{C}$, by a factor of 3.64.9, depending on the type of milk. As the frequency increased this factor tended to fall. For example, at $915 \mathrm{MHz}$ this factor fell to 2.8-3.6 and at $2450 \mathrm{MHz}$ to 1.1-2.0. For frequencies ranging from $27.12 \mathrm{MHz}$ to $915 \mathrm{MHz}$ these results agreed with the results obtained with other foodstuffs with high water content, such as liquid whey protein mixture, cooked macaroni noodles, cheese sauce (Wang et al., 2003), smashed potatoes (Guan et al., 2004) or salmon fillet (Wang et al., 2008). At $2450 \mathrm{MHz}$, the dielectric loss factor-temperature relationship showed a valley curve for RM and SM (Fig. 5). It fell gently with temperature from $20{ }^{\circ} \mathrm{C}$ to $60{ }^{\circ} \mathrm{C}$, and then increased again with temperature. A similar behaviour was observed for low bentonite content in low moisture/fat cheese (Everad et al., 2006), water paste (Luan et al., 2015) and tomatoes (Peng et al., 2013). For CNFM, dielectric loss increased with temperature. A similar behaviour was observed for medium and high moisture/fat cheese (Everad et al., 2006), flour (Bansal et al., 2015) and saline solutions (Ohlsson and Bengtsson, 1975). However, for fruit juices (Zhu et al., 2012) dielectric loss factor decreased with 
temperature at this frequency, which differs from the behaviour observed for RM, SM and CNFM.

With respect to other studies where the dielectric properties of milk were studied, the results of this work are similar to those obtained by To et al. (1974) for aqueous non-fat dry milk and Coronel et al. (2003) for skimmed milk at $915 \mathrm{MHz}$. However, results of Zhu et al. (2014) and Zhu et al. (2015a) differed considerably. In these works, the dielectric loss factor-temperature relationship showed a valley curve, for frequencies 27.12 MHz, 40.62 MHz and 915 MHz, whereas it increases clearly with temperature for other foodstuffs with high water content. These results also differed from those obtained by Coronel et al. (2003) for milk at $915 \mathrm{MHz}$. For $2450 \mathrm{MHz}$, dielectric loss factor tended to decrease with temperature, while for most foodstuffs dielectric constant tends to increase or shows a valley curve. In the previous section, these differences in the dielectric responses has already been discussed.

According to our results, dielectric milk heating was prone to runaway heating at all the frequencies studied, except for low temperatures at $2450 \mathrm{MHz}$ where dielectric loss increased with temperature. This means that warmer zones will heat faster, creating significant temperature differences in the product (Ryynänen, 1995). This is one of the most important problems of dielectric heating that contributes to overheating and product quality problems. In liquids, this problem may not be so critical because of the natural convection, mixing and turbulent flow conditions, which may help distribute heat inside the product.

The behaviour of the dielectric loss factor $\left(\varepsilon^{\prime \prime}\right)$ (no units) at the RF and $\mu \mathrm{W}$ frequency ranges can be explained by the combination of two phenomena, ionic conduction and dipole rotation, which are the dominant loss mechanisms for foodstuffs with high water content (Ryynänen, 1995):

$$
\varepsilon^{\prime \prime}=\varepsilon_{d}^{\prime \prime}+\varepsilon_{\sigma}^{\prime \prime}(5)
$$

where

$$
\varepsilon_{\sigma}^{\prime \prime}=\frac{\sigma}{2 \pi f \varepsilon_{0}}(6)
$$

By taking logarithms on both sides 


$$
\log \varepsilon_{\sigma}^{\prime \prime}=-\log f+\log \frac{\sigma}{2 \pi \varepsilon_{0}}(7)
$$

where,

subscripts $d$ and $\sigma$ stands for dipole rotation and ionic conduction contributions to dielectric constant, respectively;

$\sigma$ is the ionic conductivity of the material $(\mathrm{S} / \mathrm{m})$;

$f$ is the frequency in $\mathrm{Hz}$; and

$\varepsilon_{0}$ the permittivity of the vacuum $\left(8.854 \times 10^{-12} \mathrm{~F} / \mathrm{m}\right)$.

Ionic conduction $\varepsilon_{\sigma}^{\prime \prime}$ (no units) is dominant at frequencies below $200 \mathrm{MHz}$ and increases with temperature, while dipole rotation $\varepsilon_{d}^{\prime \prime}$ (no units) is dominant at high frequencies and tends to decrease with temperature. For instance, for aqueous ionic solutions at $\mu \mathrm{W}$ frequencies, the contribution of both phenomena is similar (Roebuck et al., 1972). $\varepsilon_{d}^{\prime \prime}$ increases when the relaxation time of polar molecules (e.g water) matches the microwave frequency (resonance frequency). Water relaxes quicker than the resonance frequency. As temperature increases, relaxation time decreases, moving farther away from the resonance frequency, absorbing less energy and decreasing the value of $\varepsilon_{d}^{\prime \prime}$. The increase of $\varepsilon_{\sigma}^{\prime \prime}$ with temperature is explained by the reduced viscosity and increased mobility of ions (Tang, 2005). According to Luan et al. (2014), the combination of these two loss mechanisms may explain the valley curve for the dielectric loss constant observed at $2450 \mathrm{MHz}$ in this study (Fig. 5).

According to Eq. 5, frequency and the dielectric loss factor will show a linear relationship in a $\log \log$ graph if dielectric loss $\varepsilon^{\prime \prime}$ is dominated by ionic conduction $\left(\varepsilon_{\sigma}^{\prime \prime}\right)$. The second term on the right side of the equation is constant because conductivity is constant for a given temperature. In Fig. 4, where dielectric loss factor versus frequency is depicted in a log-log graph, there is a linear relation with a negative slope from $15 \mathrm{MHz}$ to around $800 \mathrm{MHz}$ for all the studied temperatures. Above $800 \mathrm{MHz}$, dipole rotation losses start to contribute more to the dielectric loss, and ionic loss contribution starts to decrease. This result suggests that ionic conduction is the dominant loss mechanisms in the low range of frequencies. 
CNFM shows the highest value of dielectric loss factor at low and high frequencies, much higher than that of RM and SM. The reason for this is the higher ash content (related to salt content) which substantially increases the dielectric loss factor (Komarov et al., 2005). Fat content of CNFM milk is only $0.23 \%$ compared with $3.55 \%$ for RM and $0.63 \%$ for SM The higher fat contents of the RM and SM samples may have contributed to this result as well. According to Zhu et al. (2015b), fat occupies a volume in the conducting medium and impedes the movement of conducting ions at frequencies below $300 \mathrm{MHz}$, lowering conductivity and the dielectric loss factor. SM presents in general a higher dielectric loss factor than RM. However, ash concentration seems to dominate the heat generation. Zhu et al. (2015b), Coronel et al. (2003) and Nunes et al. (2006) observed similar results for raw and skimmed milk at $915 \mathrm{MHz}$ and above 1 $\mathrm{GHz}$, respectively.

\subsection{Penetration depth in milk}

The derived penetration depths for the studied milk types are shown in Figs. 6 to 8. As expected, the penetration depth decreased with frequency and temperature, but only slightly at high frequencies. Penetration at $20^{\circ} \mathrm{C}$ ranged from as much as $120 \mathrm{~mm}$ at RF frequencies to $20 \mathrm{~mm}$ at $\mu \mathrm{W}$ frequencies for $\mathrm{RM}$, decreasing by a factor of $1 / 6$. For the temperature range under consideration, penetration depth for RF frequencies decreased by as much as a factor of $1 / 2$ from around $120 \mathrm{~mm}$ at $20^{\circ} \mathrm{C}$ to $60 \mathrm{~mm}$ at $150{ }^{\circ} \mathrm{C}$. This decrease was much lower in the $\mu \mathrm{W}$ range as penetration depth showed small changes with temperature. Values for RM were slightly higher than for SM. CNFM presented much lower values than RM and SM. In general, foodstuffs penetration depth decreases with salt content, for example in potatoes (Guan et al., 2004).

The effect of frequency was more important than that of temperature. This behaviour is similar to that observed for whey proteins, cheese sauce and macaroni (Wang et al., 2003), fruit juices (Zhu et al., 2007), salmon (Wang et al., 2008), among others. A similar response to changes in frequency was observed for milk by Zhu et al. (2014), but with no clear trend for temperature change, which is unlike this study and other previously mentioned studies.

From these results, it can be concluded that pipe diameter for continuous treatment (up to $150{ }^{\circ} \mathrm{C}$ ) should not exceed approximately $120 \mathrm{~mm}$ for RF dielectric heating and 20 
mm for $\mu \mathrm{W}$ heating for RM and SM (Schiffmann, 1995). For CNFM these values are much lower, $80 \mathrm{~mm}$ for RF and $7.5 \mathrm{~mm}$ for $\mu \mathrm{W}$.

\section{Conclusions}

Dielectric properties of milk above $100{ }^{\circ} \mathrm{C}$ can be successfully determined. This was a novel finding in the study of the dielectric properties of milk. Dielectric properties are affected by the composition of milk, in particular the water and ash content (related to salt content). Ash content is the most important factor. Milk is prone to runaway heating across a wide range of frequencies. This poses a problem for RF thermal treatment of milk, but is not a problem for $\mu \mathrm{W}$ thermal treatment. RF dielectric heat treatment allows the use of pipes with larger diameters than $\mu \mathrm{W}$ treatment due to the higher penetration depth of RF.

\section{Acknowledgments}

The research leading to these results has received funding from the European Union's Seventh Framework Programme under grant agreement n 613732, "Enthalpy" and CERCA programme from Generalitat de Catalunya.

The authors thank Marta Garrón, Grau Matas and Cristina Canals for their valuable technical assistance. 


\section{Bibliography}

Agilent Technologies (2012). Agilent 85070E Dielectric Probe Kit. $200 \mathrm{MHz}$ to 50 GHz. Technical Overview. Publication number: 5989-0222EN. USA.

Ahmed, J.R., \& Hosahalli S. (2007). Microwave Pasteurization and Sterilization of Foods. Handbook of Food Preservation 2nd edition, 691-711.

Bansal, N., Dhaliwal, A.S., \& Mann, K.S. (2015). Dielectric properties of corn flour from 0.2 to $10 \mathrm{GHz}$. Journal of Food Engineering, 166, 255-262.

Barba, A.A., \& d'Amore, M. (2012). Relevance of Dielectric Properties in Microwave Assisted Processes, Microwave Materials Characterization. In Prof. Sandra Costanzo (Ed.), Microwave Materials Characterization (Chapter 6). InTech.

Coronel, P., Simunovic, J., \& Sandeep, K.P. (2003). Temperature profiles within milk after heating in a continous-flow tubular microwave system operating at $915 \mathrm{MHz}$. Journal of Food Science, 68(3), 1976-1981.

Datta, A.K., \& Anantheswaran, R.C. (2001). Handbook of Microwave Technology for Food Applications. In A.K. Datta and R.C. Anantheswaran (Eds). Marcel Dekker Inc., New York.

Everad C.D., Fagan, C.C., O’Donnell, C.P., O’Callaghan, D.J., \& Lyng, J.G. (2006). Dielectric properties of process cheese from 0.3 to $3 \mathrm{GHz}$. Journal of Food Engineering, $75(3), 415-422$.

FAO (2004). Code of hygienic practice for milk and milk products. Guidelines for the application and management of microbiocial steps.

ftp://ftp.fao.org/codex/meetings/CCFH/CCFH34/AnnexIIPartB.pdf

Feynman, R.P, Leighton, R.B., \& Sands, M.L. (2005). The Feynman Lectures on Physics. The definitive edition volume 2 (2nd ed.). Addison-Wesley, Boston.

García, A., Torres, J.L., Prieto, E., \& De Blas, M. (2001). Dielectric properties of grape juice at 0.2 and $3 \mathrm{GHz}$. Journal of Food Engineering 48 (3), 203-211.

Gillham, C.R., Fryer, P.J., Hasting, A.P.M., \& Wilson, D.I. (2000). Enhaced cleaning of whey protein soils using pulsed flows. Journal of Food Engineering, 46(3), 199-209.

Guan, D., Cheng, M., Wang, Y., \& Tang, J. (2004). Dielectric properties of mashed 
potatoes relevant to microwave and radio-frequency pasteurization and sterilization processes. Journal of Food Science, 69(1), 30-37.

Guo, W., Zhu, X., Liu, H., Yue, R., \& Wang, S. (2010). Effects of milk concentration and freshness on microwave dielectric properties. Journal of Food Engineering, 99, 344350.

Kaatze, U. (1989). Complex permittivity of water as a function of frequency and temperature. Journal of Chemical\&Engineering Data, 34, 371-374.

Komarov, V., Wang, S., \& Tang, J. (2005). Permittivity and Measurements. In K. Chang (Ed.), Encyclopedia of RF and Microwave Engineering (pp. 3693-3711). John Wiley \& Sons Inc., New Jersey.

Luan, D., Tang, J., Liu, F., Tang, Z., Li, F., Humin, L., \& Stewart, B. (2015). Dielectric properties of bentonite water pastes used for stable loads in microwave thermal processing systems. Journal of Food Engineering, 161, 40-47.

Mudgett, R.E. (1995). Electrical properties of food. In M.A Rao, S.S.H. Rizvi (Eds), Engineering properties of foods (pp. 389-455). Marcel Dekker, Inc., New York. Mudgett, R.E., \& Westphal, W. B. (1989). Dielectric behavior of an aqueous cation exchanger. Journal of Microwave Power and Electromagnetic Energy, 24(1), 33-37. Nelson, S.O. (1996). Review and assessment of radio-frequency and microwave energy for stored-grain insect control. Transactions of the ASAE, 39, 1475-1484.

Nelson, S.O. (2003). Frequency- and temperature-dependent permittivities of fresh fruits and vegetables from 0.01 to $1.8 \mathrm{GHz}$. Transactions of the ASAE, 46(2), $567-574$.

Nunes, A.C., Bohigas, X., \& Tejada, J. (2006). Dielectric study of milk frequencies between 1 and $20 \mathrm{GHz}$. Journal of Food Engineering, 76, 250-255.

Ohlsson, Th., \& Bengtsson N.E. (1975) Dielectric Food Data for Microwave Sterilization Processing. Journal of Microwave Power, 10(1), 94-108.

Peng, J., Tang, J., Jiao, Y., Bohnet, S.G., \& Barrett, D.M. (2013). Dielectric properties of tomatoes assisting in the development of microwave pasteurization and sterilization processes. LWT- Food Science and Technology, 54, 367-376. 
Roebuck, B. D., Goldblith, S.A., \& Westphal, W.B. (1972). Dielectric properties of carbohydrate-water mixtures at microwave frequencies. Journal of Food Science, 37, 199-204.

Ryynänen, S. (1995). The electromagnetic properties of food materials: a review of the basic principles. Journal of Food Engineering, 26, 409-429.

Schiffmann, R.F. (1995). Microwave and dielectric drying. In A.S. Mujumdar (Ed.), Handbook of Industrial Drying (p. 352). Marcel Decker, Inc., New York.

Tanaka, F., Morita, K., Mallikarjunan, P., Hung, Y.C., \& Ezeike, G.O.I. (2005).

Analysis of dielectric properties of soy sauce. Journal of Food Engineering 71 (1), 92 97.

Tang, J. (2005). Dielectric properties of foods. In H. Schubert, M. Regier (Eds.), The microwave processing of food (pp. 22-40). CRC Press, Woodhead Publishing Limited, Cambridge, London.

To, E.C., Mudgett, R.E., Wang, D.I.C., Goldblith, S.A., \& Decareau, R.V. (1974).

Dielectric properties of food materials. Journal of Microwave Power, 9(4), 303-315.

Wang, Y., Wig, T.D., Tang, J., \& Hallberg, L.M. (2003). Dielectric properties of foods relevant to RF and microwave pasteurization and sterilization. Journal of Food Engineering, 57, 257-268.

Wang, Y., Tang, J., Rasco, B., Kong, F., \& Wang, S. (2008). Dielectric properties of salmon fillets as a function of temperature and composition. Journal of Food Engineering, 87, 236-246.

Wang, J., Tang, J. M., Wang, Y. F., \& Swanson, B. (2009). Dielectric properties of egg whites and whole eggs as influenced by thermal treatments. LWT-Food Science and Technology, 42(7), 1204-1212.

Zhu, X., Guo, W., \& Wu, X. (2012). Frequency- and temperature dependent dielectric properties of fruit juices associated with pasteurization by dielectric heating. Journal of Food Engineering, 109(2), 258-266.

Zhu, X., Guo, W., \& Jia, Y. (2014). Temperature-dependent dielectric properties of raw cow's and goat's milk from 10 to $4.500 \mathrm{MHz}$ relevant to radio-frequency and microwave pasteurization process. Food Bioprocess Technology, 7, 1830-1839. 
Zhu, X., Guo, W., Jia, Y., \& Kang, F. (2015a). Dielectric properties of raw milk as functions of protein content and temperature. Food Bioprocess Technology, 8(3), 670680.

Zhu, X., Guo, W., \& Liang Z. (2015b). Determination of the Fat Content in Cow's Milk Based on Dielectric Properties. Food and Bioprocess Technology, 8(7), 1485-1494. 


\section{Figure Captions}

Fig. 1. Schematic drawing of test setup (not to scale). a: container; b: heater; c: liquid (milk, distilled water) test level; $\mathrm{d}_{1}$ : distance from the RF probe to a frontal metallic plate; $d_{2}$ : distance from the RF probe to a lateral metallic plate; $d_{3}$ : distance from the RF probe to a back metallic plate; $\mathrm{d}_{4}$ : distance from the RF probe to the liquid-air interface; e: RF probe; $f_{1}$ : movable frontal metallic plate; $f_{2}$ : movable lateral metallic plate; $f_{3}$ : movable back metallic plate; g: rigid coaxial transmission line; h: electronic calibrator; i: flexible coaxial transmission line; j: thermal shield; k: possible bubbles; 1: temperature probe.

Fig. 2. Autoclave for measuring the dielectric constant.

Fig. 3. Dielectric constants of raw milk in the $10 \mathrm{MHz}$ to $2450 \mathrm{MHz}$ frequency range at the indicated temperatures.

Fig. 4. Dielectric loss factor of raw milk in the $10 \mathrm{MHz}$ to $2450 \mathrm{MHz}$ frequency range at the indicated temperatures.

Fig. 5. Dielectric loss factor of three types of milk (RM, SM and CNFM) at $2450 \mathrm{MHz}$ and at temperatures from $20^{\circ} \mathrm{C}$ to $150{ }^{\circ} \mathrm{C}$.

Fig. 6. Penetration depth of raw milk in the $10 \mathrm{MHz}$ to $2450 \mathrm{MHz}$ frequency range at the indicated temperatures.

Fig. 7. Penetration depth of skimmed milk in the $10 \mathrm{MHz}$ to $2450 \mathrm{MHz}$ frequency range at the indicated temperatures.

Fig. 8. Penetration depth of concentrated non-fat milk in the $10 \mathrm{MHz}$ to $2450 \mathrm{MHz}$ frequency range at the indicated temperatures. 


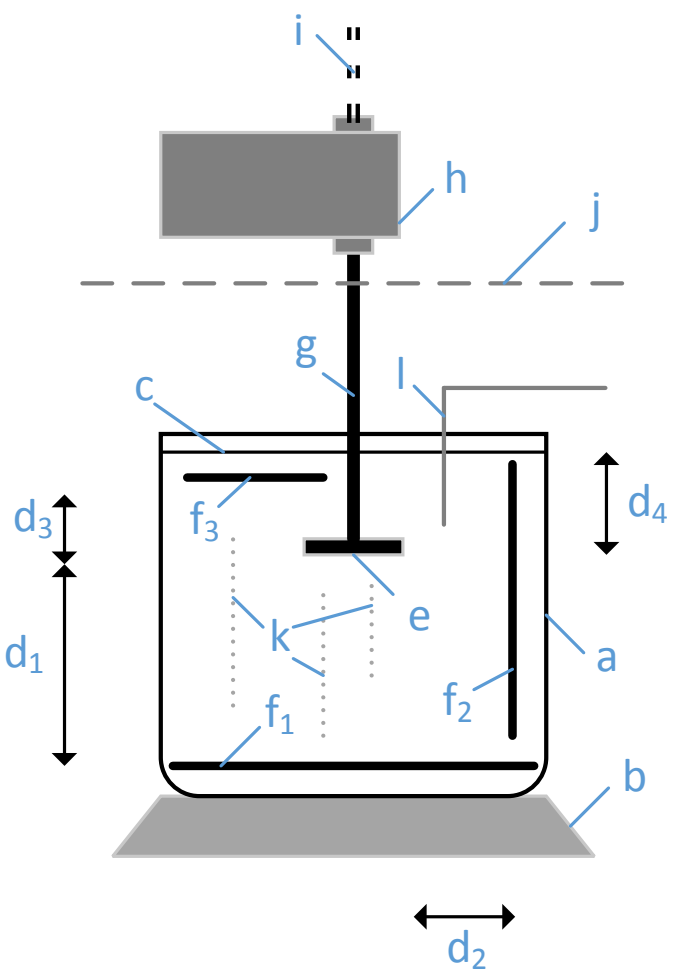

Fig. 1. Schematic drawing of test setup (not to scale). a: container; b: heater; c: liquid (milk, distilled water) test level; $\mathrm{d}_{1}$ : distance from the RF probe to a frontal metallic plate; $\mathrm{d}_{2}$ : distance from the RF probe to a lateral metallic plate; $\mathrm{d}_{3}$ : distance from the RF probe to a back metallic plate; $\mathrm{d}_{4}$ : distance from the RF probe to the liquid-air interface; e: RF probe; $f_{1}$ : movable frontal metallic plate; $f_{2}$ : movable lateral metallic plate; $f_{3}$ : movable back metallic plate; g: rigid coaxial transmission line; h: electronic calibrator; i: flexible coaxial transmission line; $\mathrm{j}$ : thermal shield; k: possible bubbles; 1: temperature probe. 


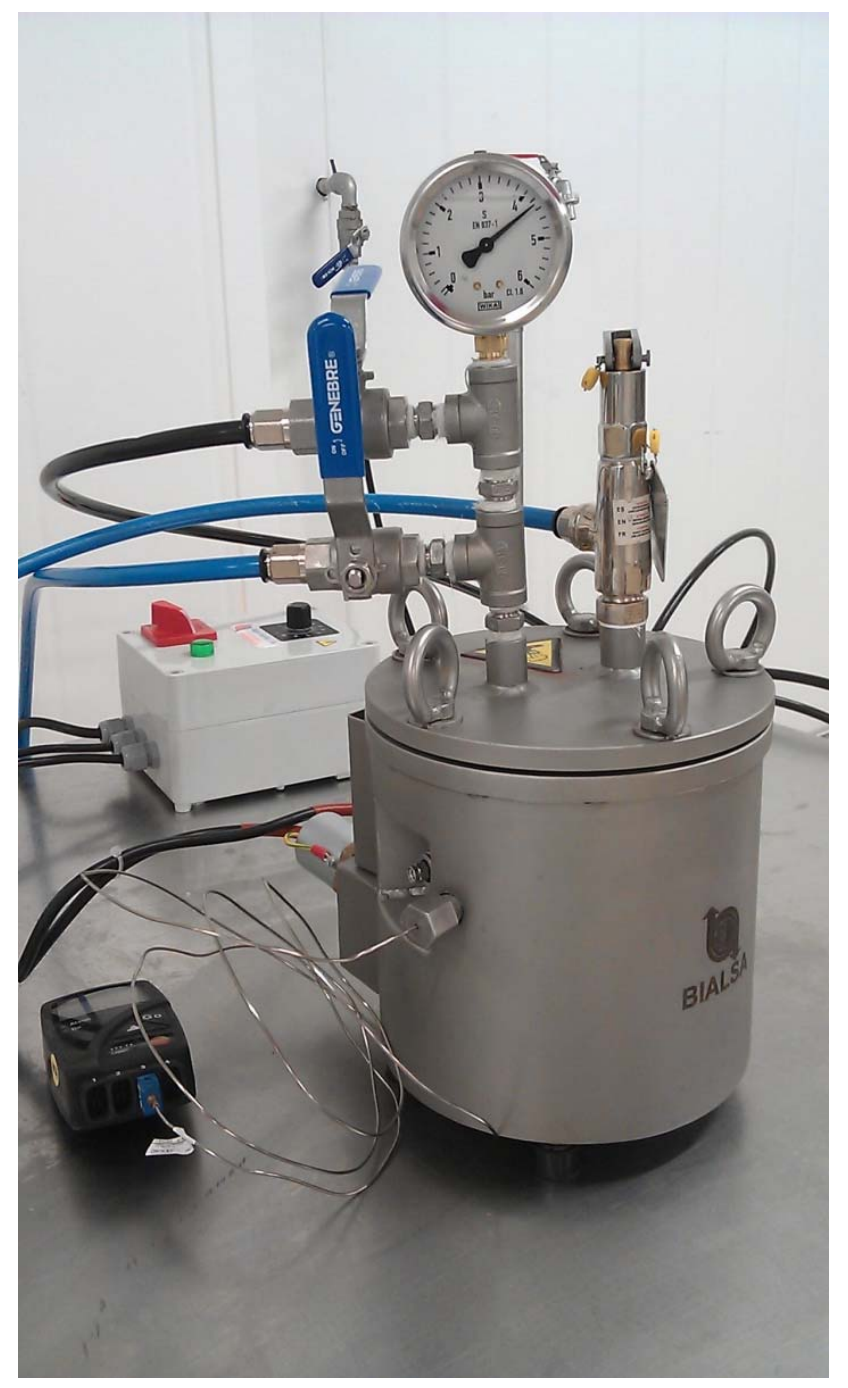

Fig. 2. Autoclave for measuring the dielectric constant. 


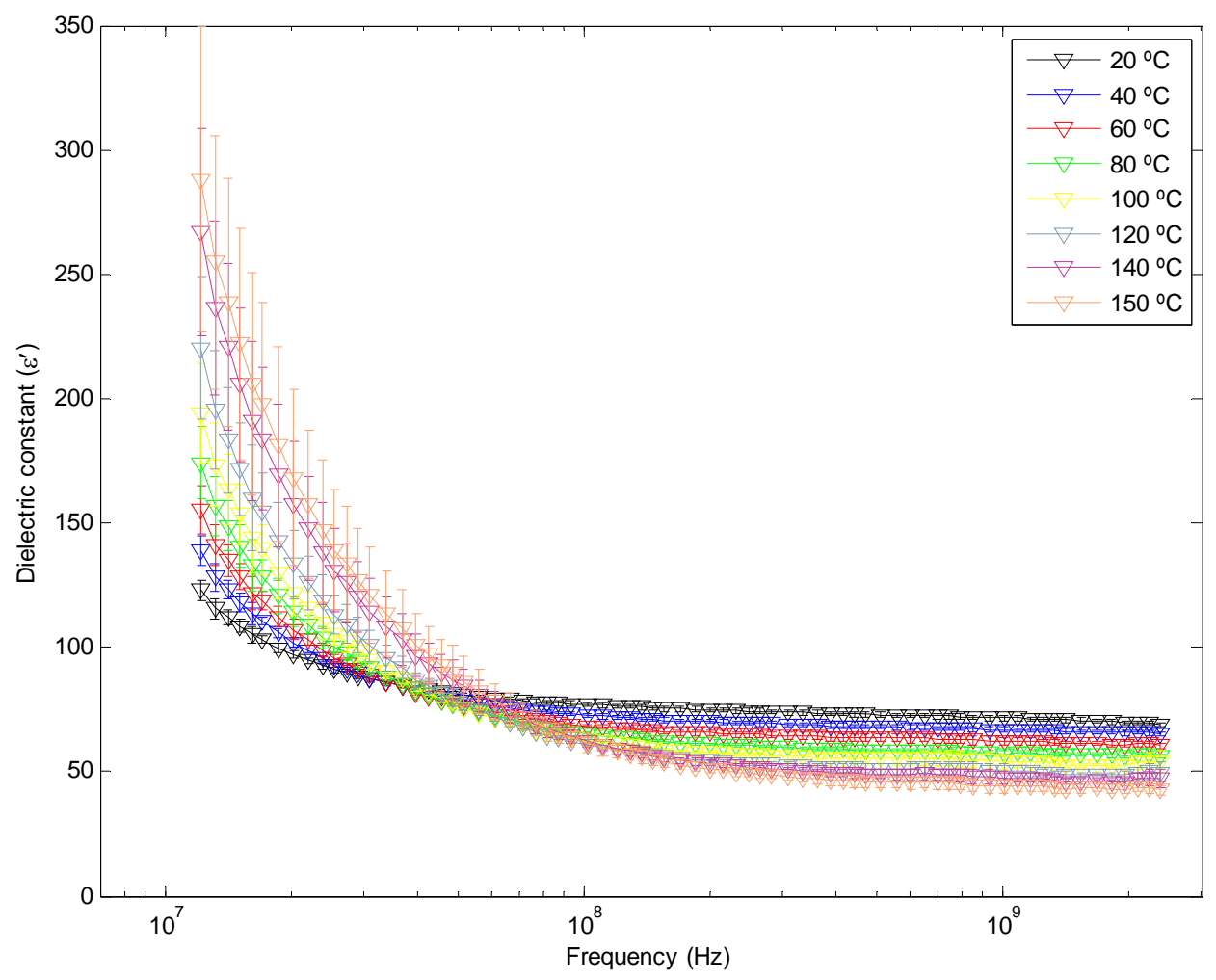

Fig. 3. Dielectric constants of raw milk in the $10 \mathrm{MHz}$ to $2450 \mathrm{MHz}$ frequency range at the indicated temperatures. 


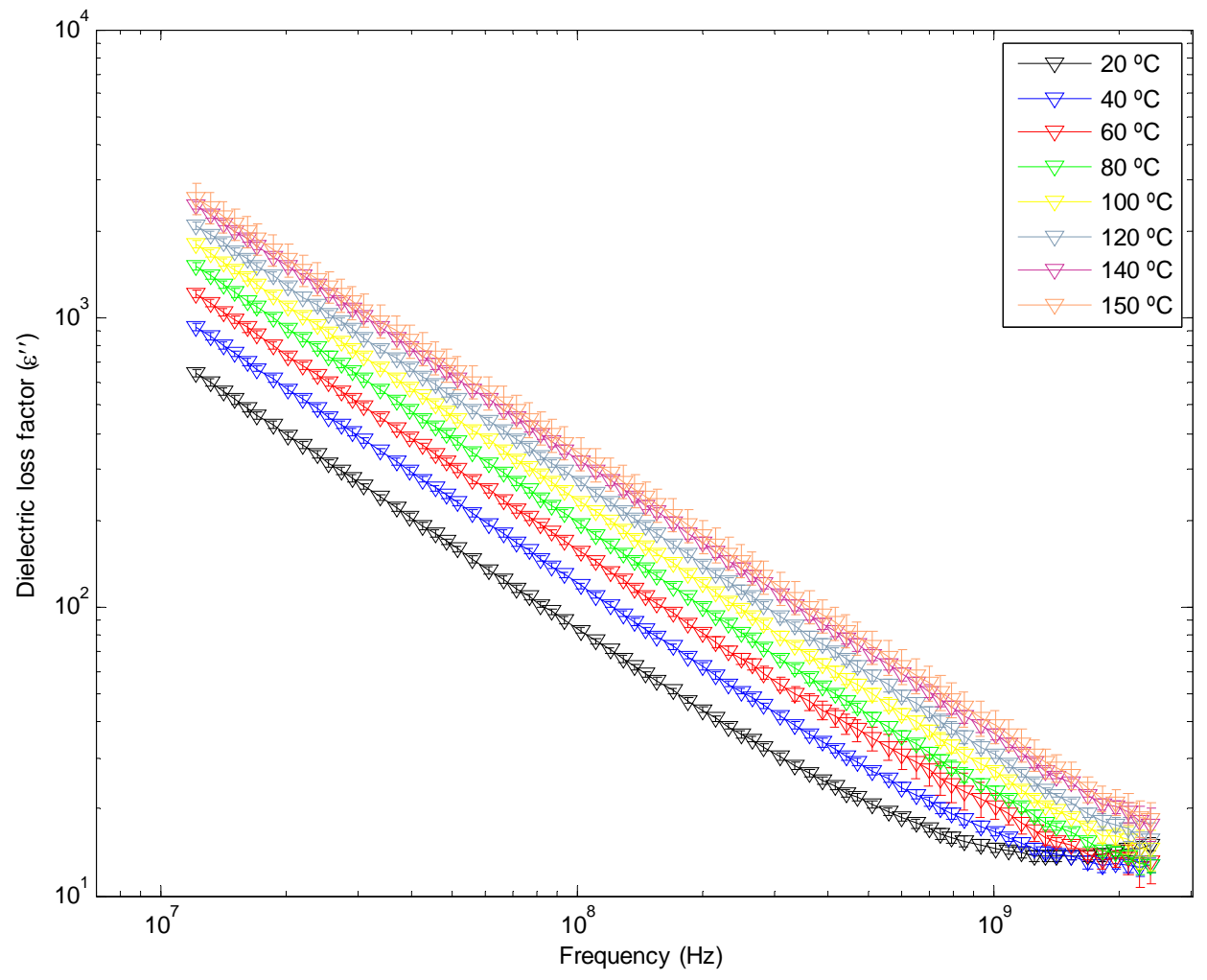

Fig. 4. Dielectric loss factor of raw milk in the $10 \mathrm{MHz}$ to $2450 \mathrm{MHz}$ frequency range at the indicated temperatures. 


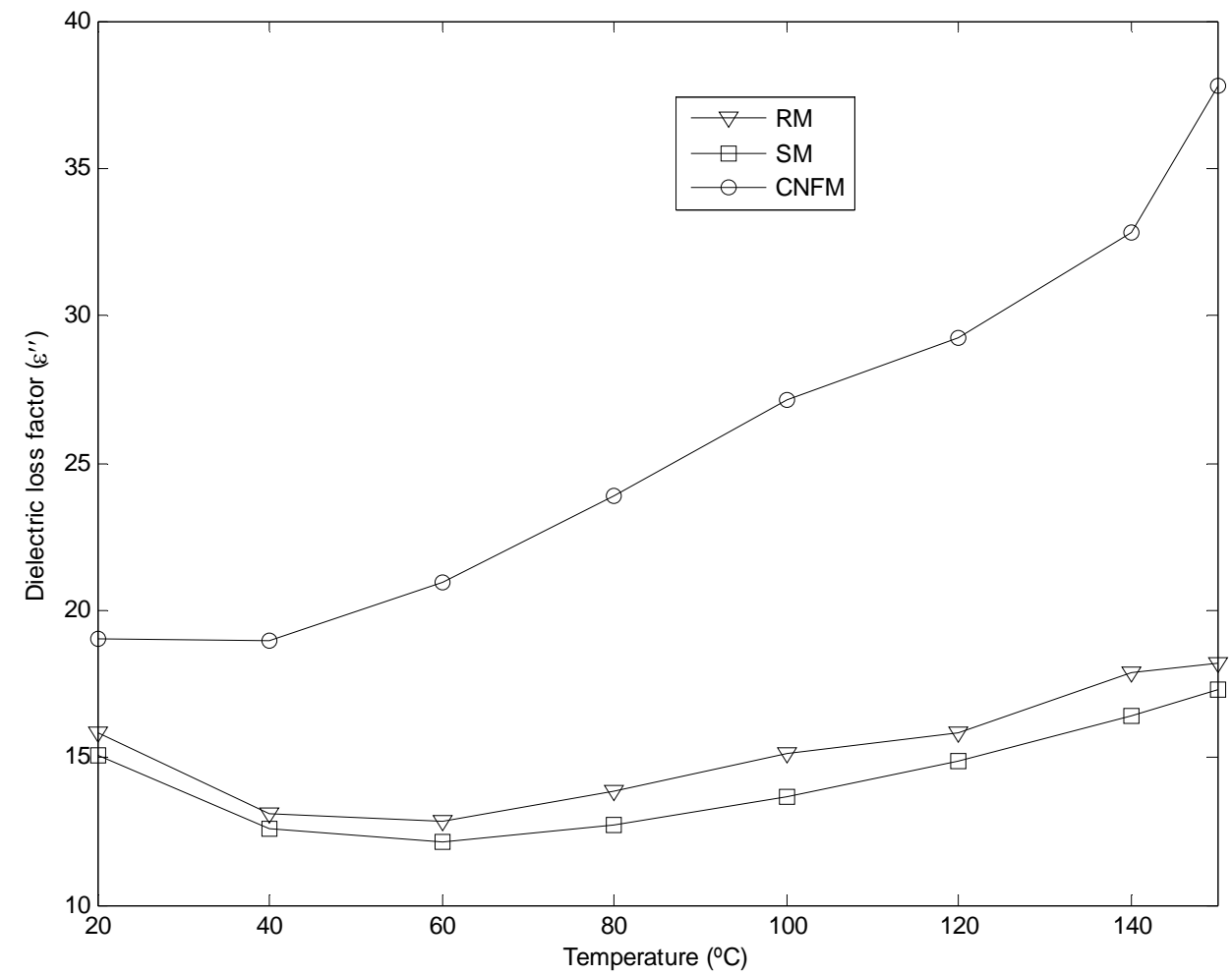

Fig. 5. Dielectric loss factor of three types of milk (RM, SM and CNFM) at $2450 \mathrm{MHz}$ and at temperatures from $20^{\circ} \mathrm{C}$ to $150{ }^{\circ} \mathrm{C}$. 


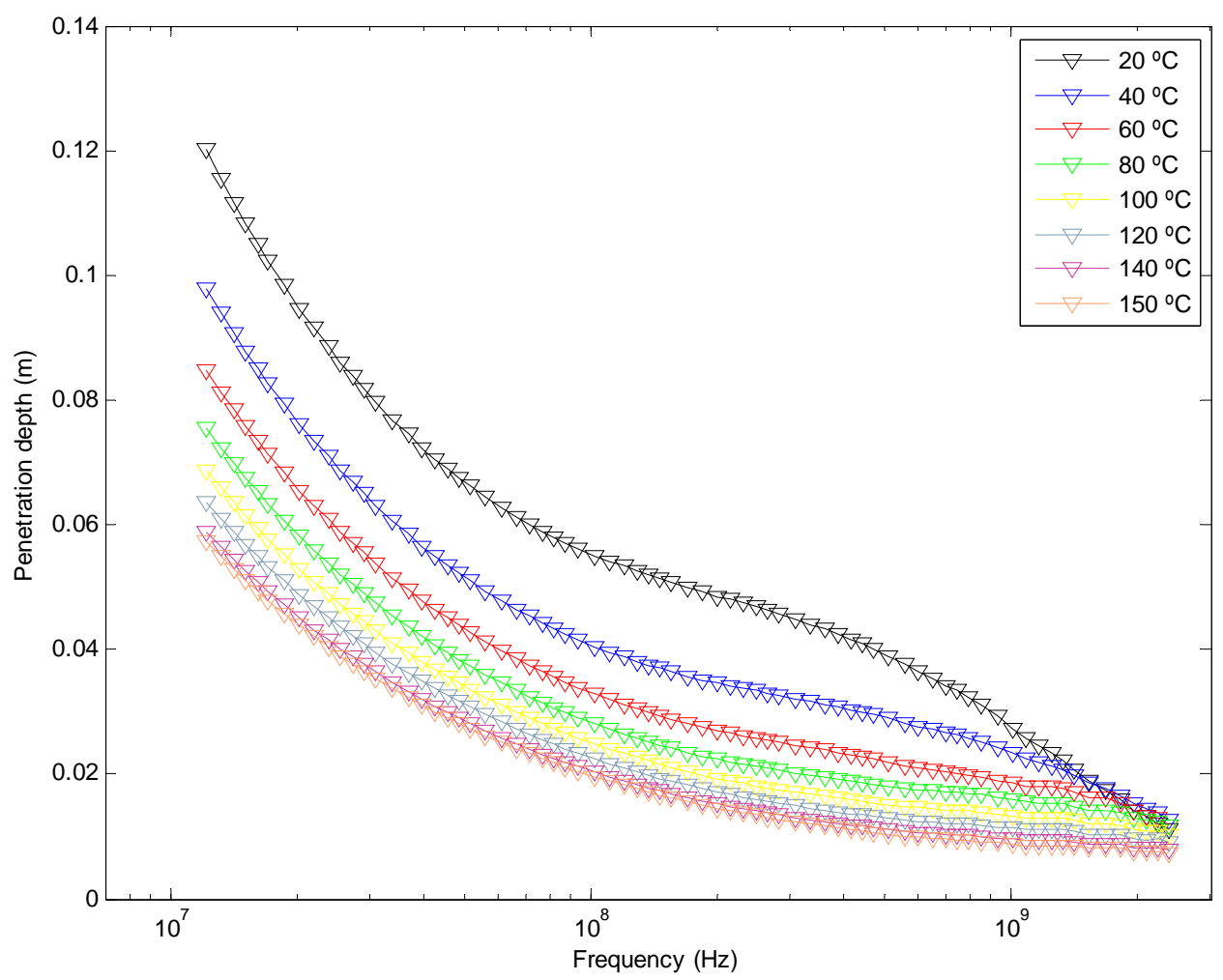

Fig. 6. Penetration depth of raw milk in the $10 \mathrm{MHz}$ to $2450 \mathrm{MHz}$ frequency range at the indicated temperatures. 


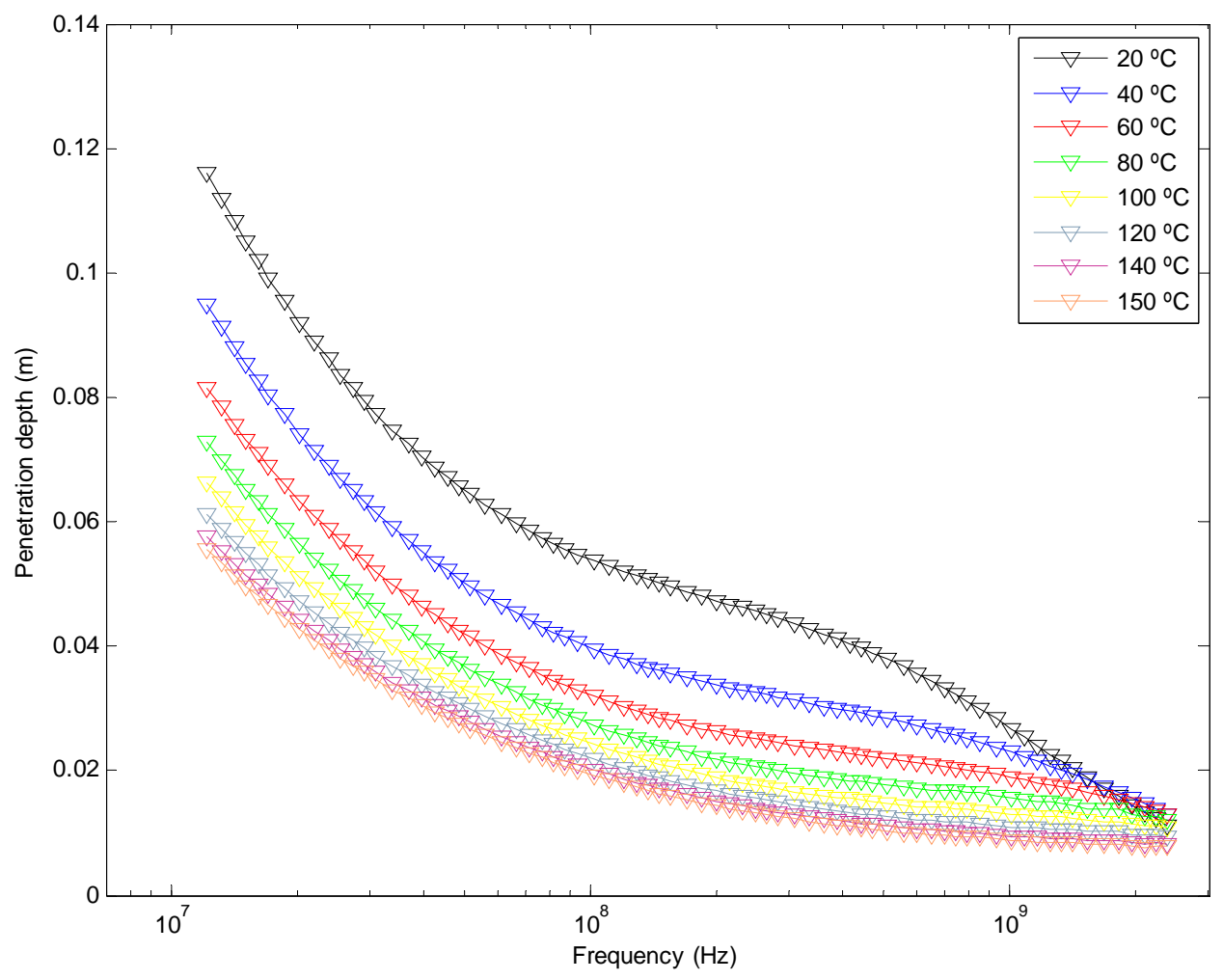

Fig. 7. Penetration depth of skimmed milk in the $10 \mathrm{MHz}$ to $2450 \mathrm{MHz}$ frequency range at the indicated temperatures 


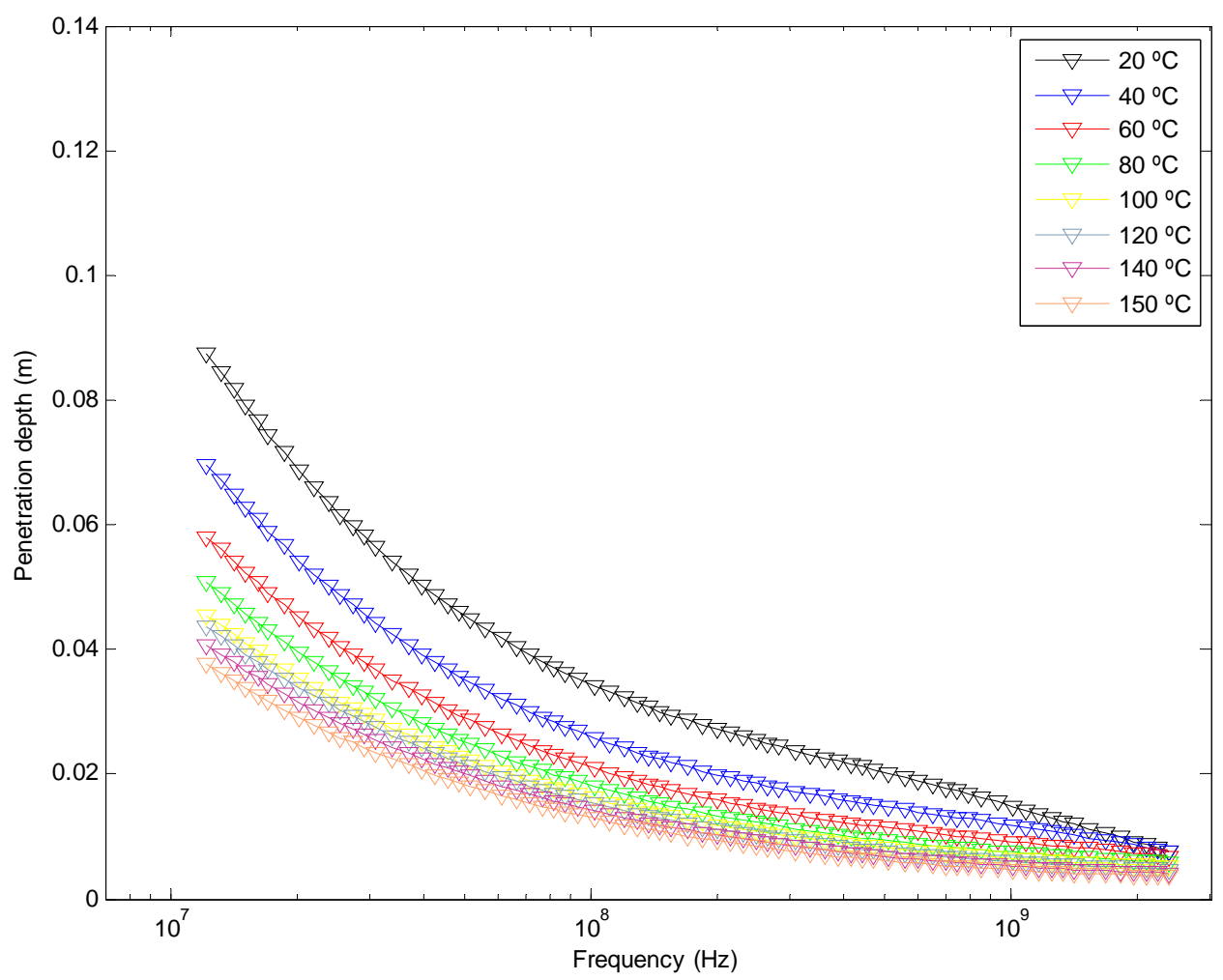

Fig. 8. Penetration depth of concentrated non-fat milk in the $10 \mathrm{MHz}$ to $2450 \mathrm{MHz}$ frequency range at the indicated temperatures. 


\begin{tabular}{cccccc}
\hline Type of milk & Water (\%) & Fat (\%) & Protein (\%) & Lactose (\%) & Ash (\%) \\
\hline RM & $88.20 \pm 0.06 \%$ & $3.55 \pm 0.02 \%$ & $3.24 \pm 0.04 \%$ & $4.68 \pm 0.02 \%$ & $0.32 \pm 0.06 \%$ \\
SM & $90.44 \pm 0.03 \%$ & $0.99 \pm 0.00 \%$ & $3.29 \pm 0.00 \%$ & $4.68 \pm 0.00 \%$ & $0.6 \pm 0.01 \%$ \\
CNFM & $65.45 \pm 0.00 \%$ & $0.23 \pm 0.00 \%$ & $11.99 \pm 0.00 \%$ & $19.39 \pm 0.00 \%$ & $2.94 \pm 0.00 \%$ \\
\hline
\end{tabular}

Table 1. Milk composition of RM, SM and CNFM samples (mean \pm standard deviation) 


\begin{tabular}{|c|c|c|c|c|c|c|c|c|c|c|}
\hline Milk type & Frequency $(\mathrm{MHz})$ & & $\begin{array}{l}\text { Temperature }\left({ }^{\circ} \mathrm{C}\right) \\
20\end{array}$ & 40 & 60 & 80 & 100 & 120 & 140 & 150 \\
\hline \multirow[t]{10}{*}{$\mathrm{RM}$} & 27.12 & $\varepsilon^{\prime}$ & $90.4 \pm 0.1$ & $91.6 \pm 1.0$ & $93.3 \pm 1.3$ & $97.7 \pm 2.7$ & $102.3 \pm 4.5$ & $109.3 \pm 7.9$ & $125.6 \pm 15.8$ & $133.7 \pm 22.3$ \\
\hline & & $\varepsilon "$ & $299.8 \pm 7.3$ & $432.7 \pm 11.2$ & $562.6 \pm 10.8$ & $706.6 \pm 19.8$ & $843.7 \pm 24.3$ & $979.8 \pm 29.9$ & $1150.2 \pm 34.6$ & $1088.5 \pm 119.3$ \\
\hline & 40.68 & $\varepsilon^{\prime}$ & $83.3 \pm 1.0$ & $81.4 \pm 1.3$ & $80.0 \pm 2.1$ & $80.5 \pm 2.6$ & $81.6 \pm 3.5$ & $84.5 \pm 4.6$ & $94.2 \pm 7.7$ & $99.6 \pm 12.1$ \\
\hline & & $\varepsilon "$ & $203.6 \pm 4.7$ & $292.0 \pm 7.9$ & $379.8 \pm 12.2$ & $476.9 \pm 14.4$ & $569.7 \pm 18.1$ & $661.9 \pm 22.7$ & $780.7 \pm 25.8$ & $830.5 \pm 84.9$ \\
\hline & 433 & $\varepsilon^{\prime}$ & $73.6 \pm 0.8$ & $68.3 \pm 1.0$ & $63.1 \pm 1.1$ & $58.8 \pm 0.8$ & $55.5 \pm 2.0$ & $51.6 \pm 1.7$ & $49.3 \pm 1.7$ & $46.4 \pm 2.0$ \\
\hline & & $\varepsilon "$ & $23.4 \pm 0.6$ & $31.3 \pm 1.0$ & $39.4 \pm 0.5$ & $49.0 \pm 1.7$ & $58.5 \pm 2.4$ & $67.6 \pm 2.8$ & $80.2 \pm 3.6$ & $85.1 \pm 9.9$ \\
\hline & 915 & $\varepsilon$ & $72.8 \pm 1.5$ & $67.6 \pm 1.6$ & $63.4 \pm 3.3$ & $59.7 \pm 5.3$ & $55.6 \pm 3.8$ & $51.4 \pm 3.3$ & $48.7 \pm 3.3$ & $44.4 \pm 2.6$ \\
\hline & & $\varepsilon "$ & $15.3 \pm 0.4$ & $17.7 \pm 0.7$ & $20.7 \pm 0.7$ & $25.0 \pm 1.1$ & $29.5 \pm 1.8$ & $33.4 \pm 1.5$ & $39.3 \pm 1.7$ & $42.0 \pm 5.2$ \\
\hline & 2450 & $\varepsilon$ & $70.3 \pm 2.2$ & $66.2 \pm 2.2$ & $62.7 \pm 4.9$ & $59.7 \pm 7.8$ & $55.0 \pm 4.5$ & $51.2 \pm 4.5$ & $48.3 \pm 4.3$ & $43.0 \pm 2.1$ \\
\hline & & $\varepsilon "$ & $15.9 \pm 0.6$ & $13.1 \pm 0.7$ & $12.9 \pm 1.2$ & $13.9 \pm 2.1$ & $15.1 \pm 2.1$ & $15.9 \pm 1.6$ & $18.0 \pm 1.8$ & $18.2 \pm 2.0$ \\
\hline \multirow[t]{10}{*}{ SM } & 27.12 & $\varepsilon^{\prime}$ & $89.7 \pm 2.7$ & $90.0 \pm 3.4$ & $91.1 \pm 4.2$ & $93.4 \pm 4.7$ & $96.5 \pm 5.1$ & $102.0 \pm 5.4$ & $113.8 \pm 5.7$ & $119.8 \pm 6.2$ \\
\hline & & $\varepsilon "$ & $310.0 \pm 2.0$ & $447.1 \pm 4.5$ & $590.6 \pm 3.4$ & $732.2 \pm 3.6$ & $873.5 \pm 5.9$ & $1020.2 \pm 6.2$ & $1159.7 \pm 11.8$ & $1239.4 \pm 19.2$ \\
\hline & 40.68 & $\varepsilon$ & $84.5 \pm 1.9$ & $82.1 \pm 2.2$ & $80.6 \pm 2.8$ & $80.5 \pm 3.2$ & $81.0 \pm 3.4$ & $83.3 \pm 3.9$ & $90.0 \pm 4.6$ & $93.6 \pm 5.1$ \\
\hline & & $\varepsilon "$ & $209.4 \pm 1.5$ & $301.9 \pm 3.6$ & $399.0 \pm 2.9$ & $494.7 \pm 2.3$ & $590.5 \pm 4.8$ & $690.1 \pm 5.2$ & $785.9 \pm 7.6$ & $842.8 \pm 12.3$ \\
\hline & 433 & $\varepsilon^{\prime}$ & $75.2 \pm 0.9$ & $70.0 \pm 0.8$ & $64.8 \pm 0.8$ & $60.0 \pm 1.0$ & $55.7 \pm 0.8$ & $51.8 \pm 0.9$ & $49.0 \pm 1.0$ & $47.5 \pm 2.5$ \\
\hline & & $\varepsilon "$ & $24.3 \pm 0.4$ & $32.2 \pm 0.6$ & $41.0 \pm 0.4$ & $50.0 \pm 0.3$ & $59.5 \pm 0.8$ & $69.7 \pm 1.1$ & $79.8 \pm 1.3$ & $85.2 \pm 1.4$ \\
\hline & 915 & $\varepsilon^{\prime}$ & $73.7 \pm 1.1$ & $68.6 \pm 0.9$ & $63.5 \pm 0.9$ & $58.7 \pm 1.1$ & $54.3 \pm 0.9$ & $50.3 \pm 1.0$ & $47.2 \pm 1.1$ & $45.6 \pm 2.7$ \\
\hline & & $\varepsilon "$ & $15.7 \pm 0.6$ & $18.2 \pm 0.6$ & $21.7 \pm 0.5$ & $25.4 \pm 0.4$ & $29.6 \pm 0.6$ & $34.4 \pm 1.0$ & $39.1 \pm 1.2$ & $41.8 \pm 1.0$ \\
\hline & 2450 & $\varepsilon^{\prime}$ & $71.2 \pm 0.9$ & $67.0 \pm 0.8$ & $62.3 \pm 0.8$ & $57.5 \pm 1.1$ & $53.3 \pm 0.8$ & $49.2 \pm 1.0$ & $46.0 \pm 1.0$ & $44.4 \pm 2.7$ \\
\hline & & $\varepsilon "$ & $15.1 \pm 0.6$ & $12.6 \pm 0.5$ & $12.1 \pm 0.6$ & $12.7 \pm 0.4$ & $13.6 \pm 0.5$ & $14.9 \pm 0.5$ & $16.4 \pm 0.5$ & $17.3 \pm 0.5$ \\
\hline \multirow[t]{10}{*}{ CNFM } & 27.12 & $\varepsilon$ & $99.1 \pm 2.9$ & $108.0 \pm 3.3$ & $119.6 \pm 5.4$ & $131.9 \pm 7.0$ & $143.7 \pm 8.2$ & $151.9 \pm 4.5$ & $178.4 \pm 13.2$ & $204.3 \pm 19.3$ \\
\hline & & $\varepsilon "$ & $536.8 \pm 1.9$ & $791.0 \pm 33.3$ & $1121.6 \pm 24.2$ & $1454.3 \pm 28.2$ & $1801.5 \pm 110.2$ & $1953.5 \pm 34.6$ & $2265.9 \pm 35.7$ & $2656.9 \pm 23.8$ \\
\hline & 40.68 & $\varepsilon$ & $87.5 \pm 0.6$ & $92.5 \pm 0.8$ & $99.0 \pm 1.8$ & $106.2 \pm 2.5$ & $112.7 \pm 2.1$ & $117.6 \pm 0.0$ & $133.4 \pm 5.6$ & $148.6 \pm 9.1$ \\
\hline & & $\varepsilon "$ & $365.6 \pm 1.5$ & $537.1 \pm 22.9$ & $760.0 \pm 17.1$ & $983.9 \pm 20.4$ & $1213.2 \pm 66.5$ & $1319.2 \pm 27.5$ & $1531.6 \pm 25.9$ & $1795.7 \pm 18.1$ \\
\hline & 433 & $\varepsilon$ & $61.6 \pm 1.5$ & $60.4 \pm 1.2$ & $58.7 \pm 1.2$ & $57.0 \pm 1.1$ & $56.6 \pm 0.2$ & $55.5 \pm 0.4$ & $53.4 \pm 1.6$ & $53.4 \pm 1.2$ \\
\hline & & $\varepsilon "$ & $43.8 \pm 0.5$ & $60.3 \pm 2.3$ & $82.3 \pm 1.7$ & $104.6 \pm 2.0$ & $125.7 \pm 3.6$ & $138.2 \pm 4.3$ & $160.8 \pm 2.6$ & $188.0 \pm 2.1$ \\
\hline & 915 & $\varepsilon^{\prime}$ & $57.7 \pm 1.4$ & $56.2 \pm 1.2$ & $54.1 \pm 1.1$ & $52.0 \pm 1.0$ & $51.3 \pm 0.3$ & $49.6 \pm 0.3$ & $46.4 \pm 1.4$ & $45.5 \pm 1.1$ \\
\hline & & $\varepsilon "$ & $26.3 \pm 0.6$ & $33.1 \pm 1.2$ & $43.0 \pm 0.9$ & $53.4 \pm 1.0$ & $63.1 \pm 1.2$ & $69.2 \pm 2.4$ & $80.0 \pm 1.3$ & $92.9 \pm 1.2$ \\
\hline & 2450 & $\varepsilon^{\prime}$ & $51.8 \pm 1.3$ & $51.6 \pm 1.5$ & $49.8 \pm 1.5$ & $47.7 \pm 1.3$ & $47.2 \pm 0.3$ & $45.4 \pm 0.1$ & $41.9 \pm 1.8$ & $40.9 \pm 1.4$ \\
\hline & & $\varepsilon "$ & $19.0 \pm 1.1$ & $19.0 \pm 1.0$ & $20.9 \pm 0.9$ & $23.9 \pm 0.9$ & $27.1 \pm 0.1$ & $29.2 \pm 1.4$ & $32.9 \pm 1.0$ & $37.8 \pm 0.9$ \\
\hline
\end{tabular}

Table 2: Dielectric constant ( $\left.\varepsilon^{\prime}\right)$ and loss factor ( $\left.\varepsilon^{\prime \prime}\right)$ (mean \pm standard deviation) of three different types of milk (raw milk (RM), skinned milk $(\mathrm{SM})$ and concentrated non-fat milk (CNFM)) at 5 frequencies (ISM Bands) and 8 temperatures. 